\title{
ADVANCES IN SOLUTION CHEMISTRY
}




\title{
ADVANCES IN SOLUTION CHEMISTRY
}

\author{
Edited by \\ I. Bertini
}

University of Florence

Florence, Italy

\section{Lunazzi}

University of Bologna

Bologna, Italy

\section{and \\ A.Dei}

University of Florence

Florence, Italy 


\section{Library of Congress Cataloging in Publication Data}

International Symposium on Solute-Solute-Solvent Interactions, 5th, Florence, Italy, 1980.

Advances in solution chemistry.

Includes index.

1. Solution (Chemistry) - Congresses. I. Bertini, Ivano. II. Lunazzi, L. III. Dei, A. IV. Title. [DNLM: 1. Solutions-Congresses. 2. Solvents-Congresses. QD 540 A244 1980]

QD540.157 1980

$541.3^{\prime} 4$

ISBN-13: 978-1-4613-3227-5

e-ISBN-13: 978-1-4613-3225-1

$80-28783$

DOI: $10.1007 / 978-1-4613-3225-1$

A part of the proceedings of the Fifth International Symposium on

Solute-Solute-Solvent Interactions, held June 2-6, 1980, in Florence, Italy

(C) 1981 Plenum Press, New York

Softcover reprint of the hardcover 1st edition 1981

A.Division of Plenum Publishing Corporation

233 Spring Street, New York, N. Y. 10013

All rights reserved

No part of this book may be reproduced, stored in a retrieval system, or transmitted, in any form or by any means, electronic, mechanical, photocopying, microfilming, recording, or otherwise, without written permission from the publisher 
PREFACE

From June 2nd to 5th 1980, the Vth International Symposium on Solute-Solute-Solvent Interactions was held in Florence, Italy. Owing to the large range of interests included in the program and to their interdisciplinary nature, a number of microsymposia on specific subjects were organized, in addition to plenary lectures, session lectures and poster sessions. The abstracts of the Conference were published in Inorganica Chimica Acta as a special publication and as an appendix to the issue of June 1980.

The plenary lectures have been published, as customary, in the Journal of Pure and Applied Chemistry (October 1980) and the results of the following microsymposia are being published in specialized journals:

1) Electronic Rearrangements Induced by Solute-Solvent Interactions (Local Editor J. H. Ammeter) - N. J. Phys. Chimie.

2) Anion Activation in Quaternary Salts, Crown Ethers, Cryptates and Related Systems (Local Editor F. Montanari) - J. Mol. Catalysis.

3) Solvent Effects in Homogeneous Catalysis By Metal Complexes (Local Editor R. Ugo) - J. Mol. Catalysis.

4) Theoretical Models in Biochemical and Related Systems (Loca1 Editor E. Clementi) - J. Computationa1 Chemistry.

5) Thermodynamic Approach in Coordinative Interactions in Solution (Local Editor P. Paoletti) - Advances in Molecular Relaxation and Interaction Processes.

The present book contains most of the session lectures as well as the contributions to the microsymposium on "Evaluation of Solvation Energies of Reagents and Transition States". The title "Advances in Solution Chemistry", although rather general and not pursuing a single definite goal, has been chosen in order to fit the frame of the title of the Symposium. The choice of the lectures 
has been based on the scientific prestige of the contributors in the various areas needed to be discussed in the meeting and, although to a lesser extent, following a geographical criterion.

The contributions to the microsymposium on "Evaluation on Solvation Energy of Reagents and Transition States" (E. Bunce1, M. H. Abraham and G. Scorrano) have been included because we thought they fit well into the overall scheme of the reactivity in solution. We acknowledge the judgement of Professor Giorgio Modena, convener of the microsymposium, for the excellent choice of speakers.

The selection of the session lectures is a result of the joint efforts of the organizing committee: U. Belluco, E. Clementi, A. Dondoni, C. Furlani, F. Montanari, L. Sacconi, R. Ugo, and the editors.

By organizing the meeting we have tried to outline the most recent aspects and trends (physical, organic, inorganic, theoretical, biological, pharmaceutical) of the chemistry of solutions. This book witnesses in part this effort.

We take the opportunity of thanking all the colleagues, friends, and students of the University of Florence, who helped in the organization of the Conference. A special thanks is due to Ms. Simonetta Donzellini who, besides delighting the participants to the meeting with her presence, patiently and skillfully retyped all the manuscripts: of all the misprints which have been left in the final draft the editors have the sole responsibility. Indeed, we decided not to return the retyped texts to the authors in order to speed up the publication.

The Editors

Firenze, 9th October 1980 


\section{CONTENTS}

Solute-Solvent Interactions as Required for the Existence of a Liquid . . . . . . . . . .

G. Resch and V. Gutmann

Thermodynamics of Aqueous Dilute Solutions of Non-Charged Molecules . . . . . . . . .

S. Cabani

Classical Ionic Fluids in the Mean

Spherical Approximation

R. Triolo and A.M. Floriano

A Comparison between Structures of Aqua and

Ammine Complexes in Solution as

Studied by an X-Ray Diffraction

Method

H. Ohtaki

Copper(II) Chelate Complexes-Solute and/or

Solvent Interactions . . . . . . . . . . .

N.D. Yordanov

Photo-Induced Ligand Solvent Interchange

in Transition Metal Complexes . . . . . . . . .

L.G. Vanquickenborne and A. Ceulemans

Mechanism of Octahedral Substitutions on

Transition Metal Complexes. Attempts

to Distinguish between $D$ and $I_{d}$

Mechanisms . . . . . . . . . . . . . .

S. Ašperger

Use of Electron Paramagnetic Resonance Spectroscopy to Study the Interaction

between Cobalt Schiff Base Complexes

and Phosphines or Phosphites in Solution . . . .

J.B. Raynor and G. Labauze 
An NMR Study of Solvent Interactions in a

Paramagnetic System . . . . . . . . . . .

R.M. Golding, R.0. Pascual, and

C. Suvanprakorn

Protonation and Complexation Equilibria of Macromolecular Bioligands in Aqueous and Mixed Solvent Solutions. The Solvent Effect . . . . . . . . . . . . .

$\mathrm{K}$. Burger and B. Nosza1

Intramolecular Hydrophobic and Aromatic-Ring

Stacking Interactions in Ternary

Complexes in Solution . . . . . . . . . . .

H. Sige1

Study on Some Dioxygen Carriers - New Models

of Natura1 Systems . . . . . . . . . . . . .

B. Jeżowska-Trzebiatowska and A.A. Vogt

Direct NMR Studies of Ionic Solvation . . . . . . . .

P. Lasz1o, A. Cornélis, A. Delville,

C. Detellier, A. Gerstmans, and

A. Stockis

NMR Studies of Calcium and Magnesium in

Biologica1 Systems . . . . . . . . . . .

S. Forsén, T. Andersson, T. Drakenberg,

E. Thulin, and T. Wieloch

Synthetic Molecular Membranes and Their

Functions . . . . . . . . . . . . . . . .

$\mathrm{T}$. Kunitake and $\mathrm{Y}$. Okahata

New Insights into the Host-Guest Solvent

Interaction of Some Inclusion Complexes.

Reaction Path Control in Cyclodextrin

Inclusion as Lyase Mode1: Solvolysis

of $\beta$-Bromoethy1-1-Naphthalene . . . . . . . .

I. Tabushi

The Composite Physica1 and Chemical Approach to the Solution Spatial Structure of

Polypeptide Neurotoxins . . . . . . . . . .

V.F. Bystrov, V.T. Ivanov, V.V. Okanov,

A.I. Miroshnikov, A.S. Arseniev,

V.I. Tset lin, V.S. Pashkov, and

E. Karlsson 
Metalloenzymes and Model Systems. Carbonic Anhydrase: Solvent and Buffer Participation, Isotope Effects, Activation

Parameters and Anionic Inhibition

Y. Pocker, T.L. Deits, and N. Tanaka

Pyridinium-N-Phenoxide Betaine Dyes as

Solvent Polarity Indicators.

Some New Findings . . . . . . . . . . . . . .

C. Reichardt, E. Harbusch, and R. Müller

Some Applications of Liquid Crystals in Organic Chemistry . . . . . . . . . . . .

G. Gottare11i and B. Samorì

Reactions and Behaviour of Organic Anions in Two-Phase Systems . . . . . . . . . . . 309

M. Makosza

Solute-Solvent Interactions in Ring Formation . . . .

C. Galli, G. Illuminati, L. Mandolini, and B. Masci

Hydrogen Acidities and Brфnsted Relations........

A. Streitwieser, Jr.

Solvent Effects on Some Nucleophilic

Substitutions

M.H. Abraham

Initial State and Transition State Solvent

Effects: Reactions in Protic and

Dipolar Aprotic Media. . . . . . . . . .

E. Buncel and E.A. Symons

Solvation Energies in Acid Catalyzed

Processes . . . . . . . . . . . . . .

G. Scorrano

Index 